\title{
Efeito das condições de germinação de girassol na redução do teor de fitato e ativação de fitase e fosfatase ácida
}

\section{Effect of sunflower germination conditions for reducing phytate content and to enhancing phytase and acid phospatase activities}

\author{
Juliana da Silva Agostini ${ }^{1}$; Elza Iouko Ida ${ }^{2 *}$
}

\section{Resumo}

\begin{abstract}
A metodologia de superfície de resposta foi aplicada para investigar o efeito do tempo e temperatura do processo de germinação na redução do teor de fitato e na ativação das enzimas fitase e fosfatase ácida de girassol híbrido(Helianthus annuus) M734. Foi utilizado o delineamento fatorial $2^{2}$ com duas repetições no ponto central com as variáveis tempo e temperatura em dois níveis, totalizando quatro experimentos com duas repetições no ponto central. Os experimentos foram conduzidos aleatoriamente e o procedimento de germinação foi realizado em câmara de germinação regulada a $25^{\circ} \mathrm{C}$ com iluminação fluorescente externa por oito dias. As sementes foram coletadas a partir do segundo dia, liofilizadas e moídas para análise de fitato e atividades de fitase e fosfatase ácida. Foi observado que o tempo e temperatura foram significativos na redução do teor de fitato e ocorrência de máxima atividades de fitase e fosfatase ácida na germinação do girassol híbrido. A maior redução do teor de fitato e máxima atividade de fosfatase ácida do girassol híbrido ocorreu no sexto dia de germinação a $30^{\circ} \mathrm{C}$. Entretanto, a máxima atividade de fitase ocorreu no quarto dia de germinação a $30^{\circ} \mathrm{C}$.
\end{abstract}

Palavras-chave: Germinação de girassol, fitato, fitase, fosafatase ácida, metodologia de superfície de resposta

\begin{abstract}
The response surface methodology was applied to investigate both length of time and temperature of the sunflower germination process on the phytate reduction and to enhancig phytase and acid phosphatase activities. The hybrid (Helianthus annuus) M734 was used and the factorial design $2^{2}$ with two repetitions at the central point working with two variables time and temperature at two levels, completing four experiments with two repetitions at central point were applied. Experiments were performed randomly and the germination process was carried out using a germination camera at $25^{\circ} \mathrm{C}$ under fluorescent illumination during 8 days. Seeds were collected from the second day of experiment, lyophilized and ground in order to process the quantitative analysis of phytate and the enzymes activity. Results showed that the length of time and temperature were significant on the reduction of phytate amount and the occurrence of the maximum enzymes activity. The maximum phytate reduction and the acid phosphatase activity was observed at the sixth day of seed germination at $30^{\circ} \mathrm{C}$ while for phytase activity the best conditions were at the fourth day at the same temperature.
\end{abstract}

Key words: Sunflower germination, phytate, phytase, acid phosphatase, response surface methodology

1 Mestre do Programa de Pós Graduação em Ciência de Alimentos da UEL

2 Doutor em Ciência de Alimentos e Professora Associada da Universidade Estadual de Londrina.Departamento de Tecnologia de Alimentos e Medicamentos/CCA.-Londrina,PR. E-mail: elida@uel.br.

* Autor para correspondência. 


\section{Introdução}

As fosfatases são enzimas amplamente distribuídas na natureza e têm a função de hidrolisar uma série de ésteres fosfatos. A fitase ou mioinositol-hexafosfato fosfohidro é uma fosfatase fitatoespecífica que catalisa a hidrólise do ácido fítico ou mio-inositol hexafosfato formando inositol e fosfatos inorgânicos. A fitase foi uma das primeiras enzimas descrita na literatura e está presente em grãos de cereais, leguminosas, oleaginosas, diversas bactérias e fungos (MAGA, 1982; REDDY; SATHE; SALUNKHE, 1982). O ácido fítico é a principal forma de armazenamento de fósforo em sementes e pólen (REDDY; SATHE; SALUNKHE, 1982). O ácido fítico está presente em muitos cereais e apresenta-se na forma de fitato como sais de potássio-magnésio (LOLAS; PALAMIDAS; MARKAKIS, 1976; O DELL; DE BOLAND, 1976). O ácido fítico devido à habilidade de formar complexos insolúveis com importantes minerais como cálcio, zinco e magnésio e também com proteínas é considerado um fator antinutricional que reduz a biodisponibilidade destes minerais (MAGA,1982). O uso de fitase seria uma alternativa interessante para hidrolisar o fitato e aumentar o valor nutricional de muitos alimentos vegetais (SEGUEILHA et al., 1992).

A função fisiológica da fitase em sementes provavelmente está relacionada com a liberação de fósforo inorgânico $(\mathrm{Pi})$ a partir do fitato, sendo que a maior proporção de Pi hidrolisado a partir do fitato é incorporado aos ácidos nucléicos. A fitase é responsável pela degradação do fitato ou pode estar relacionada a várias reações celulares com liberação de energia e na germinação de sementes tem uma importante função devido o aumento na atividade de fitase e diminuição no teor de fitatos (HOUDE; ALLI; KERMASHA, 1990). A fitase como aditivo foi aplicada em rações e alimentos para melhorar o valor nutricional após hidrólise do ácido fítico e conseqüente liberação dos ortofosfatos (GREINER; ALMINGER, 1999). Os animais monogástricos como aves, suínos e o homem consomem cereais que contém fosfato na forma de fósforo fítico e não o utilizam devido à baixa ou nenhuma atividade de fitase intestinal (WODZINSK; ULLAH, 1996). Várias tentativas de hidrólise enzimática do ácido fítico foram realizadas para melhorar o valor nutricional dos alimentos e diminuir a quantidade de fósforos excretados por esses animais, diminuindo assim problemas de poluição de fósforos em áreas de criação intensiva (SIMONS; VERSTELGH, 1990).

A fitase do girassol ainda não foi descrita, entretanto foi relatado o teor de ácido fítico de $6,1 \%$ no concentrado protéico e de $2,5 \%$ no isolado protéico (NIASI, et al., 1994). Na farinha desengordurada de girassol o teor de ácido fítico variou de 2 a 4\% conforme a variedade da planta (MILLER; PRETORIUS; TOIT, 1986; SAEED; CHERYAN, 1989).

O ácido fítico está presente em muitas sementes como principal fonte de fosfato (HAYAKAWA; TOMA; IGAUE, 1989). É um composto de ocorrência natural formado durante a maturação de muitas sementes de cereais (ERDMAN, 1979). Os cereais e oleaginosas contém cerca de 1 a $3 \%$ de ácido fítico e em quantidade menor em raízes, tubérculos, pólen, esporos e solos orgânicos (REDDY; SATHE; SALUNKHE, 1982), representando aproximadamente 60 a $90 \%$ do fósforo total (GRAF, 1983). Recentemente, Paik et al. (2004) criaram um banco de dados de alimentos que contém fitatos, sendo que o grupos de cereais apresentaram de 191,7 a 973,3 mg e o grupo de leguminosas de 508,5 a 1371,8 $\mathrm{mg}$ de fitato. Portanto, observa-se que muitos alimentos de origem vegetal contém elevado teor de fitato e em conseqüência podem diminuir a biodisponibilidade de minerais essenciais. Uma vez que o fitato pode agir como um fator antinutricional quelando minerais essenciais, a adição da fitase na dieta poderia melhorar o valor nutricional de muitos alimentos vegetais pela redução do fitato durante a digestão no estômago (SANDBERG; SVANBERG, 1991). Uma outra alternativa de reduzir o teor de ácido fítico para aumentar o valor nutricional de muitas matérias primas, seria o uso de processos como hidratação, moagem, maltagem, fermentação, 
tratamento térmico e germinação (REDDY; SATHE; SALUNKHE, 1982) ou adicionar fitases exógenas ou fitases endógenas ativadas. A obtenção de fitases efetivas a partir de fontes microbianas ou vegetais poderia ter um impacto quando aplicado durante o processamento de alimentos para remoção do fitato (GREINER; ALMINGER; CARLSSON, 2001). A hidratação de grãos de cereais, usualmente utilizado antes de processamento, pode ativar as fitases nativas, que degradam o fitato em produtos menores como penta, tetra e trifosfatos com menor habilidade de quelar os minerais (AGTE; JOSHI, 1997).

O fitato também é descrito na literatura como um antioxidante com papel benéfico na inibição de oxidação lipídica (GRAF; EATON, 1984; GRAF; EATON, 1990; LEE; HENDRICKS, 1997), nos processos crônicos como doenças cardiovasculares e câncer (CORREA, 1995; YANG; SHAMSUDIN, 1995) e outras finalidades nas áreas de farmácia, biomedicina, química e odontologia (OATWAY; VASANTHAN; HELM, 2001).

O girassol é uma oleaginosa de grande importância mundial devido à excelente qualidade do óleo comestível e aproveitamento dos subprodutos da extração, tais como, tortas ou farinhas para elaborar rações balanceadas (ROSSI, 1997). No Brasil o farelo de girassol desengordurado é uma segunda alternativa de utilização na alimentação animal e o isolado protéico para enriquecimento de produtos de panificação e derivados cárneos (REYES et al., 1985). Entretanto, o farelo contém elevado teor de ácido fítico que pode prejudicar o seu uso na alimentação humana e animal. Portanto, é de grande importância o estudo da fitase e fosfatase ácida de girassol, visando a ativação das enzimas e redução do teor de fitato que poderá melhorar a biodisponibilidade de minerais da matéria prima para elaboração de produtos alimentícios ou rações. O objetivo deste trabalho foi aplicar a metodologia de superfície de resposta para investigar o efeito do tempo e temperatura do processo de germinação do girassol híbrido MF734 na redução do teor de fitato e na ativação das atividades de fitase e fosfatase ácida.

\section{Material e Métodos}

As sementes de girassol (Helianthus annuus) híbridos M734 foram fornecidas pela Embrapa-Soja de Londrina, Pr. O teor de fitato foi determinado em triplicata para acompanhamento da germinação das sementes de girassol. As amostras foram liofilizadas e trituradas em moinho analítico com obtenção de farinhas de granulometria de 60 mesh. A extração do ácido fítico foi realizada com duas gramas de farinha em $20 \mathrm{~mL}$ de $\mathrm{HCl}$ 0,8 M com agitação a 250rpm por duas horas. Em seguida, o material foi centrifugado por 10 minutos a $2000 \mathrm{rpm}$ para obtenção do sobrenadante contendo o ácido fítico. O sobrenadante foi filtrado em papel de filtro e o teor de ácido fítico foi quantificado segundo descrição de Latta e Eskin (1980), com modificação da resina para DOWEX-AGX-4 conforme Ellis e Morris (1986). Os resultados foram expressos em $\mathrm{g}$ de fitato/ $100 \mathrm{~g}$ de amostra em base seca.

A atividade de fitase foi determinada em triplicata conforme o método de Lolas e Markakis (1977). O $\mathrm{P}_{\mathrm{i}}$ liberado pela hidrólise enzimática do fitato foi determinado conforme o método de molibdato de amônio modificado por Heinonen e Lahti (1981). Uma unidade internacional de atividade de fitase (1UI) foi definida como mmoles de $\mathrm{P}_{\mathrm{i}}$ liberado / minuto nas condições do ensaio.

A atividade de fosfatase ácida foi medida em triplicata pela liberação de $p$-nitrofenol do $p$ nitrofenilfosfato de acordo com o método descrito por Gibson e Ullah (1988). Uma unidade internacional de atividade de fosfatase ácida (1UI) foi expressa como $\eta$ moles de $p$-nitrofenol liberado/minuto nas condições do ensaio.

Inicialmente, as sementes de girassol foram sanitizadas com soluções de Tween- 80 0,1\% por cinco minutos, $\mathrm{NaOCl} 0,5 \%$ por dois minutos e $\mathrm{H}_{2} \mathrm{O}_{2} 0,75 \%$ por um minuto, seguidas de enxágüe com água esterilizada para remover os resíduos sanitizantes conforme técnica descrita por Konietzny, Greiner e Jany (1995). Para o processo de germinação, foram distribuídas 50 sementes sobre duas folhas de papel de germinação, cobertas com mais uma folha, enroladas e 
colocadas em câmara de germinação regulada a $25^{\circ} \mathrm{C}$ com iluminação fluorescente externa por oito dias. Os cotilédones foram coletados a partir do segundo até o oitavo dia de germinação, liofilizadas e moídas para análises de fitato, atividades de fitase e fosfatase ácida.

A metodologia de superfície de resposta foi utilizada para testar o efeito do tempo e temperatura de germinação do girassol híbrido MF734 na redução do teor de fitato e na ativação das enzimas fitase e fosfatase ácida. Para o processo de germinação do girassol foi utilizado o delineamento fatorial $2^{2} \mathrm{com}$ duas repetições no ponto central com duas variáveis (tempo e temperatura) em dois níveis (Tabela 2), totalizando quatro tratamentos e duas repetições no ponto central. Os experimentos foram conduzidos aleatoriamente e o procedimento de germinação conforme descrito anteriormente. As variáveis independentes (Tabela 1) foram estabelecidas com ensaios preliminares e foram: $\mathrm{X} 1=$ tempo de germinação (dias) e X2 = temperatura de germinação $\left({ }^{\circ} \mathrm{C}\right)$. As variáveis dependentes ou funções-respostas foram: $\mathrm{Y} 1=\%$ do teor de fitato, $\mathrm{Y} 2=$ atividade de fitase (U/g de amostra) e Y3 = atividade de fosfatase ácida (U/g de amostra).

Tabela 1. Variáveis independentes e níveis de variação do processo de germinação do girassol híbrido

\begin{tabular}{c|ccc}
\hline Variáveis independentes & \multicolumn{3}{c}{ Níveis de variação } \\
\cline { 2 - 4 } & $\mathbf{- 1}$ & $\mathbf{0}$ & $\mathbf{+ 1}$ \\
\hline $\mathrm{X} 1=$ tempo de germinação (dias) & 4 & 5 & 6 \\
$\mathrm{X} 2=$ temperatura de germinação $\left({ }^{\circ} \mathrm{C}\right)$ & 18 & 24 & 30 \\
\hline
\end{tabular}

Tabela 2. Delineamento experimental do processo de germinação do girassol híbrido M734

\begin{tabular}{c|c|c|c|c}
\hline \multirow{2}{*}{ Ensai os } & \multicolumn{2}{|c|}{ Variáveis codificadas } & \multicolumn{2}{c}{ Variáveis reais } \\
\cline { 2 - 5 } & $\mathbf{x 1}$ & $\mathbf{x 2}$ & $\mathbf{X 1}$ & $\mathbf{X 2}$ \\
\hline 1 & +1 & +1 & 6 & 30 \\
2 & +1 & -1 & 6 & 18 \\
3 & -1 & +1 & 4 & 30 \\
4 & -1 & -1 & 4 & 18 \\
5 & 0 & 0 & 5 & 24 \\
6 & 0 & 0 & 5 & 24 \\
\hline
\end{tabular}

A análise de regressão e variância foram realizadas com o programa Statistical Analysis System (SAS), 1998 e os mapas de contorno de superfície de resposta foram construídos utilizando o programa STATISTICA 5.1. A fórmula geral do modelo de superfície de resposta foi expressa a partir da equação1:

$\mathrm{Y}=\mathrm{b}_{0}+\mathrm{b}_{1} \mathrm{x}_{1}+\mathrm{b}_{2} \mathrm{x}_{2}+\mathrm{b}_{12} \mathrm{x}_{1} \mathrm{x}_{2}+\mathrm{e}$ (equação 1)

sendo:

$\mathrm{Y}=$ função resposta

$\mathrm{x}_{1}$ e $\mathrm{x}_{2}=$ variáveis codificadas

$\mathrm{b} \cdot \mathrm{s}=$ coeficientes estimados pelo modelo de superfície de resposta

$\mathrm{e}=$ resíduo (erro experimental)

\section{Resultados e Discussão}

O efeito do tempo (X1) e da temperatura de germinação (X2) do girassol híbrido M734 e suas combinações no teor de fitato e nas atividades das enzimas foi investigado conforme planejamento experimental (Tabela 1). As funções respostas observadas $(\mathrm{Y} 1=\%$ do Teor de fitato; $\mathrm{Y} 2=$ Atividade de fitase em U/g de amostra) e Y3 = Atividade de fosfatase ácida em U/g de amostra) e estimadas ( $\hat{Y} 1$, $\hat{\mathrm{Y}} 2$ e $\hat{\mathrm{Y}} 3)$ para os seis ensaios do delineamento experimental estão apresentados na Tabela 3. As análises de variância das funções respostas Y1, Y2 e Y3 estão apresentadas nas Tabela 3. O coeficiente de determinação total ( $\mathrm{R}^{2}$ ajustado) foi igual a 0,9712 para a função resposta $\mathrm{Y} 1 ; 0,9750$ para a função resposta Y2 e 0,8907 para a função resposta Y3, ou 
seja, 97,12; 97,50 e 89,07\% da variação para as três funções respostas Y1, Y2 e Y3, respectivamente, foram explicados pelo modelo com bom ajuste aos dados experimentais. As baixas variabilidades dos resultados obtidos foram confirmadas pelos respectivos coeficientes de variação (cv) de 1,07; 1,48 e 3,02\%, para as funções respostas Y1, Y2 e Y3. A falta de ajuste não foi significativa em nenhuma das funções respostas, indicando assim um bom ajuste do modelo matemático utilizado.

Tabela 3. Funções respostas observadas e estimadas do teor de fitato (Y1 e $\hat{Y} 1)$, atividades de fitase (Y2 e $\hat{\mathrm{Y}} 2)$ e fosfatase ácida (Y3 e Ŷ3) em função do tempo e da temperatura de germinação do girassol híbrido M734

\begin{tabular}{ccccccc}
\hline Ensai os & Y1 & $\hat{\mathbf{Y}} \mathbf{1}$ & $\mathbf{Y 2}$ & $\hat{\mathbf{Y}} \mathbf{2}$ & $\mathbf{Y 3}$ & $\hat{\mathbf{Y}} \mathbf{3}$ \\
\hline 1 & 0,61 & 0,56 & 1,25 & 1,28 & 77,79 & 81,49 \\
2 & 1,47 & 1,42 & 0,56 & 0,59 & 24,84 & 28,54 \\
3 & 0,74 & 0,69 & 1,50 & 1,54 & 66,19 & 69,89 \\
4 & 2,67 & 2,62 & 0,18 & 0,21 & 3,58 & 7,28 \\
5 & 1,21 & 1,32 & 0,96 & 0,90 & 55,10 & 46,80 \\
6 & 1,23 & 1,32 & 0,98 & 0,90 & 53,30 & 46,80 \\
\hline
\end{tabular}

$\mathrm{cv}=1,07 \%$ para o $\mathrm{Y} 1 ; 1,48 \%$ para o $\mathrm{Y} 2$ e $3,03 \%$ para o $\mathrm{Y} 3$

Considerando que na análise de variância a regressão completa foi significativa, pode-se obter o modelo matemático de superfície de resposta estimada (equação 1) através dos respectivos coeficientes das equações 2, 3 e 4 para o teor de fitato ( $\hat{Y} 1)$ e atividades de fitase ( $\hat{Y} 2)$ e fosfatase ácida ( $\hat{Y} 2)$ de sementes de girassol germinadas.

$\hat{\mathrm{Y}} 1(\%$ do teor de fitato $)=11,1292-1,4037 \mathrm{x}_{1}-$ $0,3393 x_{2}+0,0446 x_{1} x_{2}$ (equação 2)

$\hat{\mathrm{Y}} 2$ (atividade de fitase) $=-4,4520+0,6687 \mathrm{x}_{1}+$ $0,2165 \mathrm{x}_{2}-0,0265 \mathrm{x}_{1} \mathrm{x}_{2}$ (equação 3 )

$\hat{\mathrm{Y}} 3$ (atividade de fosfatase ácida) $=-158,153+$ $17,879 x_{1}+6,828 x_{2}-0,403 x_{1} x_{2}$ (equação 4 )

A análise de variância para a função resposta $\hat{Y} 1$ (\% do teor de fitato) apresentada na Tabela 4 indica que o tempo $\left(\mathrm{x}_{1}\right)$, temperatura $\left(\mathrm{x}_{2}\right)$ e interação $\left(\mathrm{x}_{1} \mathrm{x}_{2}\right)$ influenciaram significativamente no teor de fitato na germinação do girassol híbrido M734. Na equação 2, observa-se que os dois coeficientes são negativos e, conseqüentemente as variáveis tempo $\left(\mathrm{x}_{1}\right)$ e temperatura $\left(\mathrm{x}_{2}\right)$ influenciaram negativamente no teor de fitato na germinação, sendo que o tempo $\left(\mathrm{x}_{1}\right)$ influenciou de forma mais relevante, ou seja, cerca de quatro vezes em relação a temperatura de germinação. Foi observado também por vários pesquisadores que a germinação de muitos grãos reduziu significativamente o teor de fitato, tais como canola (LU et al., 1987), feijão fava (ESKIN; WIEB, 1983), milho (CHANG; 1967), ervilha (CHEN; PAN, 1977) e trigo (EASTWOOD; LAIDMAN, 1971). Em geral, os grãos contém fitatos que são as principais formas de armazenamento de fósforo e inositol (COSGROVE, 1966) e a maior parte dos fósforos transportados na germinação são provenientes do fitato (ASSADA; TANAKA; KASAI, 1969). 
Agostini, J. S.; Ida, E. I.

Tabela 4. Análises de variância para os efeitos de tempo e temperatura de germinação sobre o teor de fitato (Regressão 1), atividade de fitase (Regressão 2) e fosfatase ácida (Regressão 3) de girassol híbrido M734

\begin{tabular}{l|c|c|c|c}
\hline \multicolumn{1}{|c|}{ Fonte de Variação } & $\begin{array}{c}\text { Graus de } \\
\text { Liber dade }\end{array}$ & $\begin{array}{c}\text { Soma dos } \\
\text { Quadrados }\end{array}$ & F & P \\
\hline Regressão 1 & 1 & 0,4428 & 2214,4510 & $0,0135^{*}$ \\
$\quad$ Tempo & 1 & 1,9446 & 9723,1510 & $0,0064^{*}$ \\
Temperatura & 1 & 0,2867 & 1433,801 & $0,0168^{*}$ \\
Interação & 1 & 0,0309 & 154,534 & 0,5110 \\
Falta de ajuste & 1 & 0,0002 & & \\
Erro puro & 1 & 0,0040 & 22,339 & 0,1327 \\
Regressão 2 & 1 & 1,0130 & 5612,422 & $0,0084^{*}$ \\
Tempo & 1 & 0,1014 & 562,007 & $0,0268^{*}$ \\
Temperatura & 1 & 0,0011 & 61,507 & 0,0807 \\
Interação & 1 & 0,0001 & & \\
Falta de ajuste & 1 & 270,076 & 166,899 & $0,0491^{*}$ \\
$\quad$ Erro puro & 1 & 3338,413 & 2063,040 & $0,0140^{*}$ \\
Regressão 3 & 1 & 23,339 & 14,423 & 0,1639 \\
Tempo & 1 & 164,413 & 101,603 & 0,0629 \\
Temperatura & 1 & 1,6118 & & \\
Interação & 1 & & \\
Falta de ajuste & 1 &
\end{tabular}

significativo a $5 \%$ de probabilidade

A análise de variância para a função resposta $\hat{Y} 2$ (atividade de fitase) apresentada na Tabela 4 indica que a temperatura $\left(\mathrm{x}_{2}\right)$ e a interação $\left(\mathrm{x}_{1} \mathrm{x}_{2}\right)$ foram significativas para a atividade de fitase na germinação do girassol híbrido M734. Na equação 3, observa-se que as variáveis tempo $\left(\mathrm{x}_{1}\right)$ e temperatura $\left(\mathrm{x}_{2}\right)$ de germinação influenciaram positivamente na atividade de fitase, enquanto que a interação $\left(\mathrm{x}_{1} \mathrm{x}_{2}\right)$ influenciou na diminuição da atividade de fitase. Várias investigações relataram que as condições de hidratação prévia e o tempo e temperatura de germinação de milho, soja, ervilhas, feijões e tremoço também foram importantes para obtenção de máxima atividade de fitase (LOLAS; MARKAKIS, 1977; CHANG; SHWIMMER; BURR, 1977; BEAL; METHA, 1985; BARTNIK; SZAFRANSKAA, 1987; LABOURE; GAGNON; LESCURE, 1993; HAMADA, 1996; SILVA; TRUGO, 1996).

Para a função resposta $\hat{Y} 3$ (atividade de fosfatase ácida), a análise de variância (Tabela 4) indicou que o tempo $\left(\mathrm{x}_{1}\right)$ e temperatura $\left(\mathrm{x}_{2}\right)$ na germinação do girassol híbrido M734 foram significativos no aumento da atividade de fosfatase ácida. A equação 4 indicou que o tempo $\left(\mathrm{x}_{1}\right)$ influenciou em cerca de três vezes em relação a temperatura $\left(\mathrm{x}_{1}\right)$ de germinação na atividade da fosfatase ácida. Centeno et al. (2001) germinaram centeio e cevada e observaram que o teor de fósforo fítico diminuiu e as atividades de fitase e fosfatases ácidas aumentaram.

Para confirmar o efeito do tempo $\left(\mathrm{x}_{1}\right)$ e temperatura $\left(\mathrm{x}_{1}\right)$ de germinação, foram calculadas as funções respostas estimadas ( $\hat{Y} 1, \hat{Y} 2$ e $\hat{Y} 3)$ a partir das equações 2, 3 e 4 e funções respostas observadas (Y1, Y2 e Y3) na Tabela 3. Para a função resposta observada Y1 (\% do teor de fitato), fixandose o tempo $\left(\mathrm{x}_{1}\right)$ igual a seis dias na equação 2 , observa-se que conforme aumenta a temperatura $\left(\mathrm{x}_{2}\right)$ de germinação (ensaios 1 e 2), o teor de fitato estimado ( $\hat{Y} 1)$ diminui para os respectivos ensaios com um teor mínimo de fitato no ensaio $1 \mathrm{em}$ relação ao ensaio 2. Ainda na equação 2 , fixando-se a temperatura $\left(\mathrm{x}_{2}\right)$ igual a $18^{\circ} \mathrm{C}$, observa-se que nos ensaios 2 e 4 , à medida que aumenta o tempo $\left(\mathrm{x}_{1}\right)$ de germinação, reduz o teor de fitato. Para as funções respostas observadas Y2 (atividade de fitase) e Y3 (atividade de fosfatase ácida), observa-se que 
fixando-se o tempo $\left(\mathrm{x}_{1}\right)$ igual a quatro dias nas equações 3 e 4, à medida que aumenta a temperatura $\left(\mathrm{x}_{2}\right)$ de germinação, as funções respostas estimadas $\hat{\mathrm{Y}} 2$ e $\hat{\mathrm{Y}} \mid 3$ aumentaram nos ensaios 3 e 4 , com um máximo de atividade para as duas enzimas (ensaio 3) em relação ao ensaio 4. Fixando-se a temperatura $\left(\mathrm{x}_{2}\right)$ igual a $18^{\circ} \mathrm{C}$ (equações 3 e 4 ), observa-se que à medida que aumenta o tempo $\left(\mathrm{x}_{1}\right)$ de germinação, ocorre aumento nas atividades de fitase e fosfatase ácida (ensaios 3 e 4).

Assim, o modelo matemático estimou que na região experimental do processo de germinação, o teor mínimo de fitato e atividade máxima de fosfatase ácida ocorreram quando se utilizou $\mathrm{x}_{1}$ igual a tempo de seis dias e $\mathrm{x}_{2}$ igual a temperatura de $30^{\circ} \mathrm{C}$. Entretanto, a atividade máxima de fitase foi obtida quando se utilizou $\mathrm{x}_{1}$ igual a tempo de quatro dias $\mathrm{e}$ $\mathrm{x}_{2}$ igual a temperatura de $30^{\circ} \mathrm{C}$.

As condições de tempo e temperatura de germinação de muitas sementes influenciam as mudanças no teor de fitato e atividades de fitase e fosfatase ácida. Segundo Houde, Alli e Kermasha (1990), a fitase é responsável pela degradação do fitato ou está ligada a várias reações celulares relacionadas com liberação de energia da planta. A atividade de fitase em sementes maduras é reduzida devido o pequeno efeito do fitato sobre as sementes secas ou dormentes (MAGA, 1982). O aumento da atividade de fitase na germinação de semente ocasionou decréscimo no teor de fitato, movendo as reservas de fósforo para a germinação e seu crescimento (KONIETZNY; GREINER; JANY,1995). Não está claro se esse aumento na atividade foi resultado de ativação da enzima préexistente ou síntese de novo da proteína (GIBSON; ULLAH, 1988; SILVA; TRUGO, 1996). Assim, dependendo do tipo de cereal e condições de germinação observa-se que ocorre variação na atividade de fitase e fosfatase ácida com redução no teor de fitato.
As superfícies de respostas dos efeitos do tempo $\left(\mathrm{x}_{1}\right)$ e temperatura $\left(\mathrm{x}_{2}\right)$ de germinação das três funções respostas (Y1, Y2 e Y3) foram elaboradas a partir das equações 2, 3 e 4 e estão apresentadas nas Figuras 1, 2 e 3.

Na Figura 1, observa-se que a superfície de resposta apresenta uma tendência de que quando aumenta o tempo $\left(\mathrm{x}_{1}\right)$ e temperatura $\left(\mathrm{x}_{2}\right)$ de germinação, a \% do teor de fitato (Y1) diminui. A superfície de resposta apresenta o teor mínimo de fitato igual a $\mathrm{Y} 1=0,61 \%$ quando $\mathrm{x}_{1}$ é igual a +1 , ou seja, seis dias de germinação e $\mathrm{x}_{2}$ é igual $\mathrm{a}+1$, ou seja, temperatura de $30^{\circ} \mathrm{C}$.

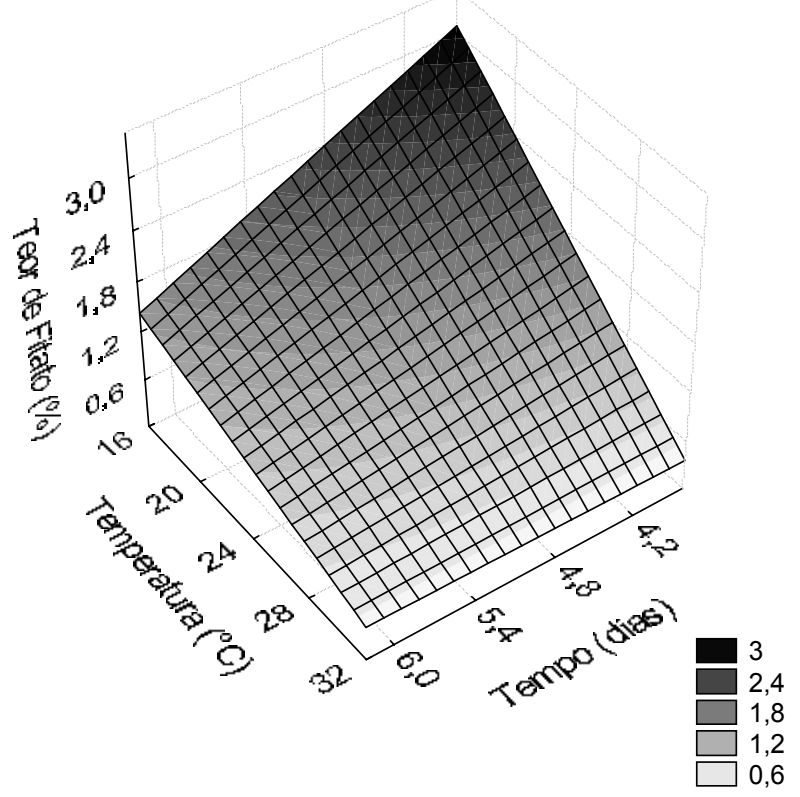

Figura 1. Superfície de resposta do efeito do tempo e temperatura de germinação no teor de fitato de girassol híbrido M734

Na Figura 2, visualiza-se a superfície de resposta para a função resposta Y2 (atividade de fitase) indicando que à medida que aumenta a temperatura de germinação, a atividade da fitase também aumenta, independentemente do intervalo de tempo de quatro a seis dias de germinação. A atividade máxima de fitase (Y2 = 1,505 U/g) foi obtida quando $\mathrm{x}_{1}$ é igual a -1 , ou seja, tempo de germinação de quatro dias, e $\mathrm{x}_{2}$ é igual a +1 , ou seja, temperatura de $30^{\circ} \mathrm{C}$. 


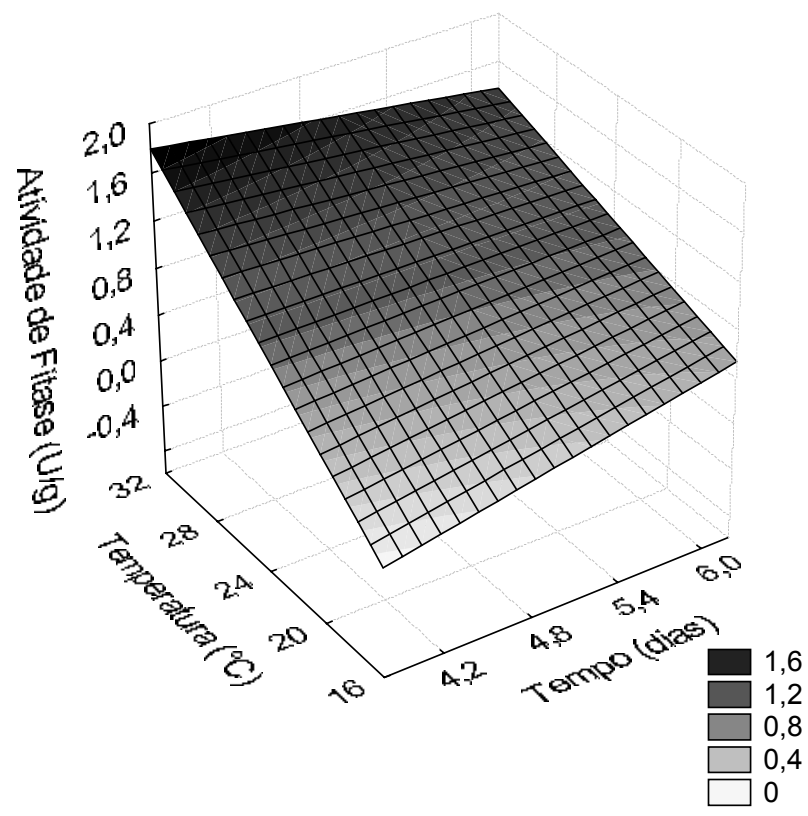

Figura 2. Superfície de resposta do efeito do tempo e temperatura de germinação na atividade de fitase de girassol híbrido M734

A superfície de resposta para a função resposta Y3 (atividade de fosfatase ácida) está apresentada na Figura 3, e observa-se uma tendência de que quando aumenta o tempo e temperatura de germinação, a atividade de fosfatase ácida aumenta. A atividade máxima de fosfatase ácida $(77,790 \mathrm{U} / \mathrm{g})$ foi obtida quando $\mathrm{x}_{1}$ é igual a +1 , ou seja, tempo de germinação de seis dias, e $x_{2}$ igual a +1 , ou temperatura de $30^{\circ} \mathrm{C}$.

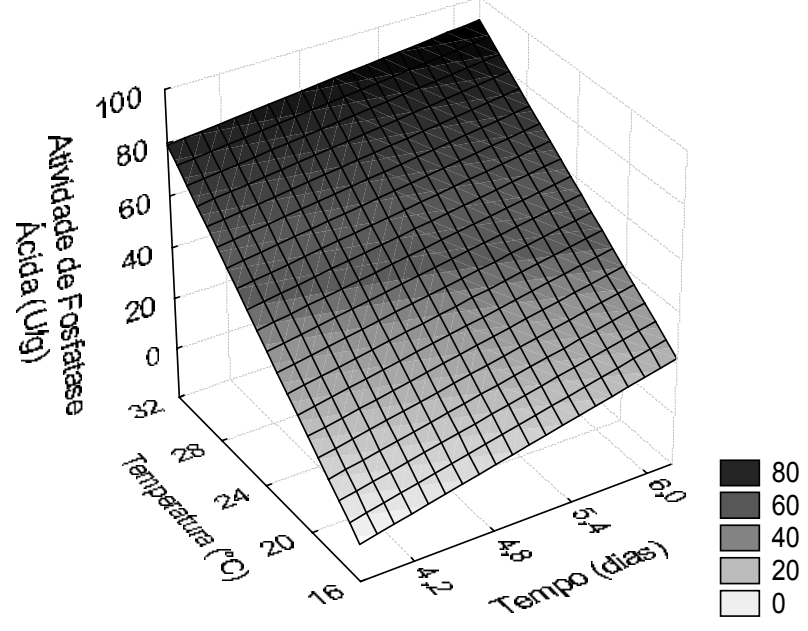

Figura 3. Superfície de resposta do efeito do tempo e temperatura de germinação na atividade de fosfatase ácida de girassol híbrido M734

\section{Conclusões}

O tempo e temperatura foram significativos na germinação do girassol híbrido M734 para redução do teor de fitato e ocorrência de máxima atividades de fitase e fosfatase ácida. A maior redução do teor de fitato e máxima atividade de fosfatase ácida do girassol híbrido ocorreu no sexto dia de germinação a $30^{\circ} \mathrm{C}$. Entretanto, a máxima atividade de fitase ocorreu no quarto dia de germinação a $30^{\circ} \mathrm{C}$.

\section{Agradecimentos}

Ao Conselho Nacional de Desenvolvimento Científico e Tecnológico-CNPq, pela concessão da bolsas de estudo e recursos financeiros e à Embrapasoja de Londrina-Pr pelo fornecimento das sementes de girassol.

\section{Referências}

AGTE, V. V.; JOSHI, S. R. Effect of traditional food processing on phytate degradation in wheat and millets. Journal of Agricultural and Food Chemistry, Washington, v.45, n.5, p.1659-1661, 1997.

ASSADA, K.; TANAKA, K.; KASAI, Z. Formation of phytic acid in cereal grains. Annals of the New York Academy Of Sciences, New York, v.165, n.A2, p.801-814, 1969.

BARTNIK, M.; SZAFRANSKAA, I. Changes in phytate content and phytase activity during the germination of some cereals. Journal of Cereal Science, London, v.5, n.1, p.23-28, 1987.

BEAL, L.; MEHTA, T. Zinc and Phytate distribution in peas, influence of heat treatmente, germination, $\mathrm{pH}$, substrate, and phosphorus on pea phytate and phytase. Journal of Food Science, Chicago, v.50, n.1, p.96-101, 1985.

CENTENO, C.; VIVEROS, A.; BRENES, A.; CANALES, R.; LOZANO, A.; CUADRA, C. Effect of several germination conditions on total $\mathrm{P}$, phytate $\mathrm{P}$, phytase and acid phosphatase activities and inositol phosphate esters en rye and barley. Journal of Agricultural and Food Chemistry, Easton, v.49, p.3208-3215, 2001.

CHANG, C. W. Study of phytase and fluoride effects in germinating corn seeds. Cereal Chemistry, Saint Paul, v.44, n.2, p.129-142, 1967. 
CHANG, R.; SCHWIMMER, S.; BURR, H. K. Phytate: Removal from Whole dry beans by enzimatic hydrolysis and diffusion. Journal of Food Science, Chicago, v.42, n.4, p.1098-1101, 1977.

CHEN, L. H.; PAN, S. H. Decrease of phytates during germination of pea seeds (Pigsum sativa). Nutrition Reports International, Los Altos, v.16, n.1, p.125-131, 1977.

CORREA, P. The role of antioxidants in gastric carcinogens. Critical Reviews in Food Science and Nutrition, Boca Raton, v.35, n.1-2, p.59-64, 1995.

COSGROVE, D. J. The chemistry and biochemistry of inositol polyphosphates. Pure and Applied Chemistry, Oxford, v.16, p.209-224, 1966.

EASTWOOD, D.; LAIDMAN, D. The mobilization of macronutrients elements in germinating wheat grain. Phytochemistry, New York, v.10, n.6, p.1275-1284, 1971.

ELLIS, R.; MORRIS, R. Appropriate resin selection for rapid phytate analysis by ion exchange chromatography. Cereal Chemistry, Saint Paul, v.63, n.1, p.58-59, 1986.

ERDMAN JR, J. W. Oilseed phytates:Nutritional implications. Journal of the American Oil Chemists Society, Chicago, v.56, n.8, p.736-741, 1979.

ESKIN, N. A. M.; WIEBE, S. Changes in phytase activity and phytate during germination of two fababean cultivars. Journal of Food Science, Chicago, v.48, n.1, p.270-271, 1983.

GIBSON, D. M.; ULLAH, A. H. J. Purification and characterization of phytase from cotyledons of germinating soybean seeds. Archives of Biochemistry and Biophysics, New York, v.260, n.3, p.503-513, 1988.

GRAF, E.; EATON, J. W. Antioxidant functions of phytic acid. Free Radical Biology \& Medicine, New York, v.8, n.1, p.61-69, 1990.

GRAF, E.; EATON, J. W. Effects of Phytate on mineral bioavailability in mice. Journal of Nutrition, Philadelphia, v.114, n.7, p.1192-1198, 1984.

GRAF, E. Aplications of phytic acid. Journal of American Oil Chemists Society, Chicago, v.60, n.11, p.1861-1867, 1983.

GREINER, R.; ALMINGER, M. L. Purification and characterization of phytate-degrading enzyme from germinated oat (Avena sativa). Journal of the Science of Food and Agriculture, London, v.79, n.11, p.1453-1460, 1999.

GREINER, R.; ALMINGER, M. L.; CARLSSON, N. Stereospecificity of myo-inositol hexakisphosphate dephosphorylation by a phytate-degrading enzyme of baker's yeast. Journal of Agricultural and Food Chemistry, Easton, v.49, n.5, p.2228-2233, 2001.
HAMADA, J. S. Isolation and Identification of the multiple forms of soybean phytases. Journal of American Oil Chemists Society, Chicago, v.73, n.9, p.1143-1151, 1996.

HAYAKAWA, T.; TOMA, Y.; IGAUE, I. Purification e characterization of acid phosphatases with or without phytase activity from rice bran. Agricultural and Biological Chemistry, Tokyo, v.53, n.6, p.1475-1483, 1989.

HEINONEN, J. K.; LAHTI, R. J. A new convenient colorimetric determination of inorganic orthophosphate and its application to the assay of inorganic pyrophosphatase. Analytical Biochemistry, New York, v.113, n.2, p.313-317, 1981.

HOUDE, R. L.; ALLI, I.; KERMASHA, S. Purification and characteriztion of canola seed (Brassica sp.) phytase. Journal of Food Biochemistry, Westport, v.14, n.5, p.331351, 1990.

KONIETZNY, U.; GREINER, R.; JANY, K-D. Purification and characterization of a phytase from spelt. Journal of Food Biochemistry, Westport, v.18, n.3, p.165-183, 1995.

LABOURE, A.; GAGNON, J.; LESCURE, A. Purification and characterization of a phytase (myoinositolhexaphosphate phosphohydrolase) accumulated in maize (zea mays) seedlings during germination. The Biochemical Journal, London, v.295, p.413-419, 1993.

LATTA, M.; ESKIN, M. A simple and rapid colorimetric method for phytate determination. Journal of Agricultural and Food Chemistry, Easton, v.28, n.6, p.1313-1315, 1980.

LEE, B. J.; HENDRICKS, D. G. Metal-catalyzed oxidation of ascorbate,deoxyribose and linoleic acid as affected by phytic acid in a model system. Journal of Food Science, Chicago, v.62, n.5, p.935-938, 1997

LOLAS, G. M.; PALAMIDAS, N.; MARKAKIS, P. The phytic acid-total phosphorus relationship in barley, oats, soybeans, and wheat. Cereal Chemistry, Saint Paul, v.53, n.6, p.867-871, 1976.

LOLAS, G. M.; MARKAKIS, P. The phytase of navy beans. (Phaseolus vulgaris). Journal of Food Science, v.42, n.4, p.1094-1106, 1977.

LU, S.; KIM, H.; ESKIN, N. A. M.; LATTA, M.; JOHNSON, S. Changes in phytase activity and phytate during the germination of six canola cultivars. Journal of Food Science, Chicago, v.52, n.1, p.173-175, 1987.

MAGA, J. A. Phytate: Its chemistry, ocurrence, food interactions, nutritional significance, and methods of analysis. Journal of Agricultural and Food Chemistry, Easton, v.30, n.1, p.1-9, 1982.

MILLER, N.; PRETORIUS, H. E.; TOIT, L. J. Phytic acid in sunflower seeds, pressed cake and protein concentrate. Food Chemistry, London, v.21, n.3, p.205-209, 1986. 
NIASI, A. H. K.; KAUSAR, T.; ISHAQUE, W.; ABID, K. M. Nutritional quality of sunflower protein concentrate and isolate. Science International, v.6, n.3, p.249-250, 1994.

O’DELL, B. L.; DeBOLAND, A. R. Complexation of phytate with protein and cátions in corn germ and oilseed meals. Journal of Agriculture and Food Chemistry, Easton, v.24, n.4, p.804-808, 1976.

OATWAY, L.; VASANTHAN, T.; HELM, J. H. Phytic acid. Food Reviews International, New York, v.17, n.4, p.419431, 2001.

PAIK, H. T.; SHIM, J. E.; JOUNG, H.; NAM, G.; LEE, J.; SHIM, J. E. Biovailabilable zinc intake of Korean adults in relation to the phytate content of Korean foods. Journal of Food Composition and Analysis, San Diego, v.17, p.713724, 2004.

REDDY, N. R.; SATHE, S. K.; SALUNKHE, D. K. Phytates in legumes and cereals. Advances in Food Research, San Diego, v.28, p.1-92, 1982.

REYES,F.G.R.; GARIBAY,C.B.;UNGARO,C.B.; TOLEDO, M. C. F. Girassol: Cultura e aspectos químicos, nutricionais etecnológicos. Campinas: Fundação Cargil, 1985.

ROSSI, R. O. Girassol. Curitiba: Tecnoagro, 1997.

SAEED, M.; CHERYAN, M. Sunflower protein concentrates and isolates low in polyphenols and phytates. Journal of Food Science, Chicago, v.53, n.4, p.1127-1131, 1989.
SANDBERG, A. S.; SVANBERG, U. Phytate hydrolysis by phytase in cereal; Effects on vitro estimation of iron availability. Journal of Food Science, Chicago, v.56, n.5, p.1330-1333, 1991.

SEGUEILHA, L.; LAMBRECHTS, C.; BOZE, H.; MOULIN, G.; GALZY, P. Purification and properties of the phytate from Schwanniomyces castellii. Journal of Fermentation and Bioengineering, Osaka, v.74, n.1, p.7-11, 1992.

SILVA, L. G.; TRUGO, L. C. Characterization of phytase activity in lupin seed. Journal of Food Biochemistry, Westport, v.20, n.4, p.329-340, 1996.

SIMONS, P. C.; VERSTEEGH, H. A. J. Improvement of phosphorus availability by microbial phytase in broilers and pigs. British Journal of Nutrition, Cambridge, v.64, n.2, p.525-540, 1990.

WODZINSK, R. J.; ULLAH, A. H. J. Phytase. Advances in Applied Microbiology, San Diego, v.42, p.263-302, 1996.

YANG, G. Y., SHAMSUDDIN, A. M. IP6-induced growth inhibition and differentiation of HT-29 human colon cancer cells: involvemente of intacellular inositol phosphates. Anticancer-Research, Atenas, v.15, n.6B, p.24792487,1995. 